\title{
Orthorexic tendencies in the general population: association with demographic data, psychiatric symptoms, and utilization of mental health services
}

\author{
Martin Greetfeld ${ }^{1} \cdot$ Johannes Baltasar Hessler-Kaufmann ${ }^{1,2} \oplus \cdot$ Beate Brandl $^{3} \cdot$ Tomas Skurk $^{3} \cdot$ Christina Holzapfel $^{5}$. \\ Norbert Quadflieg ${ }^{2} \cdot$ Sandra Schlegl ${ }^{2} \cdot$ Hans Hauner $^{4,5} \cdot$ Ulrich Voderholzer $^{1,2,6}$
}

Received: 19 March 2020 / Accepted: 10 July 2020 / Published online: 29 July 2020

(c) The Author(s) 2020

\begin{abstract}
Purpose Orthorexia nervosa $(\mathrm{ON})$ is characterized by a preoccupation to eat healthily and restrictive eating habits despite negative psychosocial and physical consequences. As a relatively new construct, its prevalence and correlates in the general population and the associated utilization of mental health services are unclear.

Methods Adults from the general population completed the Düsseldorf Orthorexia Scale (DOS), the Patient Health Questionnaire (PHQ), the Short Eating Disorder Examination (SEED).

Results Five-hundred eleven (63.4\% female) participants with a mean age of 43.39 ( $S D=18.06)$ completed the questionnaires. The prevalence of ON according to the DOS was $2.3 \%$. Considering only effects of at least intermediate size, independent samples $t$-tests suggested higher DOS scores for persons with bulimia nervosa $(p<.001$, Cohen's $d=1.14)$, somatoform syndrome $(p=.012, d=.60)$, and major depressive syndrome (compared $p<.001, d=1.78$ ) according to PHQ as well as those who reported to always experience fear of gaining weight $(p<.001, d=1.78)$. The DOS score correlated moderately strong and positively with the PHQ depression $(r=.37, p<.001)$ and stress $(r=.33, p<.001)$ scores as well as the SEED bulimia score $(r=.32, p<.001)$. In multivariate logistic regression analyses, only PHQ depression scores were associated with past psychotherapeutic or psychiatric treatment $(\mathrm{OR}=1.20, p=.002)$ and intake of psychotropic medication in the last year $(\mathrm{OR}=1.22, p=.013)$.

Conclusions The prevalence of ON was low compared to international studies but is in line with other non-representative German studies. Orthorexic tendencies related to general mental distress and eating disorder symptoms but were no independent reason for seeking treatment.

Level of evidence Level V, cross-sectional descriptive study.
\end{abstract}

Keywords Eating behaviors $\cdot$ Eating disorder $\cdot$ Mental health care $\cdot$ Population studies

While not being recognized as an official disorder, proposed criteria for orthorexia nervosa $(\mathrm{ON})$ include a preoccupation

The article is part of the Topical Collection on Orthorexia Nervosa.

Martin Greetfeld

MGreetfeld@schoen-klinik.de

1 Schoen Clinic Roseneck, Am Roseneck 6, 83209 Prien Am Chiemsee, Germany

2 Department of Psychiatry and Psychotherapy, University Hospital, LMU Munich, Munich, Germany

3 ZIEL-Institute for Food \& Health, Technical University of Munich, Freising, Germany with food and restrictive eating habits despite negative physiological, emotional, or psychosocial consequences [1]. Partly due to the questionable quality of the respective assessment tools [2-4] and the lack of a well-defined

4 Chair of Nutritional Medicine, Else Kröner-Fresenius Center for Nutritional Medicine, Technical University of Munich, Freising-Weihenstephan, Germany

5 Institute for Nutritional Medicine, School of Medicine, Technical University of Munich, Munich, Germany

6 Department of Psychiatry and Psychotherapy, University Hospital of Freiburg, Freiburg, Germany 
criterion for calculating optimal cut-offs, prevalence estimates of ON vary considerably. Despite limitations [3], the Düsseldorf Orthorexia Scale (DOS [5]) appears to be the most suitable questionnaire $[4,6]$ at the moment and has been translated to English [7], Spanish [8], and Chinese [9]. Hence, the following overview of the literature only includes studies using the DOS in the general population or student samples. Studies with selected populations like vegans [10] and athletes [11] were not considered, as these characteristics might influence prevalence rates and correlates of $\mathrm{ON}$.

In a representative sample of the German population, the DOS with its proposed cut-off (above 95th percentile in the validation sample: score $\geq 30$ ) yielded a prevalence of $\mathrm{ON}$ of $6.9 \%$ [12]. In non-representative German samples of varying size, including matched control groups of clinical samples and participants of an online survey, estimates range between 3 and 4\% [5, 13-15]. These numbers are contrasted by studies from the USA [7], China [9], and Spain [16] that reported rates up to $10 \%$ in smaller student samples.

Higher DOS scores in general population samples are often associated with eating disorder symptoms $[5,9,15$, 16]. The higher rates in women suggested by some studies $[5,17,18]$, however, are likely due to sample characteristics and not actual sex differences with regard to symptoms of ON [19]. The two studies that examined the association of DOS scores with psychiatric symptoms reported positive associations with depressive, anxious, obsessive, and compulsive symptoms, as well as negative associations with well-being and life satisfaction $[12,15]$. One study reported higher rates of current psychotherapeutic treatment and use of psychotropic medication in persons with higher DOS scores [15]. Table 1 gives an overview of studies using the DOS for prevalence estimates and correlational analyses.

Given the smaller number of prevalence estimates of ON based on the DOS in the general population and the limited data on the association of DOS scores with psychiatric symptoms as well as the utilization of mental health services, the aims of the present study were to examine (1) the prevalence of ON according to the DOS, (2) the association of DOS scores with demographic data and other psychiatric symptoms, as well as (3) the independent association of DOS scores with the utilization of psychotherapeutic and psychiatric treatment to explore to whether orthorexic tendencies are relevant for mental health services.

\section{Methods}

\section{Participants and procedures}

Participants $(N=511,63.4 \%$ female $)$ were recruited from two studies on nutrition and metabolism that were conducted at the Institute for Nutritional Medicine at the Technical
University of Munich [20, 21]. Inclusion criteria for participation in these studies were age $\geq 18$ years, body mass index $(B M I) \geq 18.5$, absence of severe diseases, no surgery within the last 3 months, and no acute physical impairment. Using the existing personal data from these studies, the participants were contacted and asked whether they would like to take part in another study related to eating attitudes and habits. A set of questionnaires was completed either at the study center or mailed to the participants. A reminder was sent to those who did not respond after 1 month.

Mean age of the 511 participants was 43.4 years ( $\mathrm{SD}=18.1$, range 18-84) and mean BMI was $25.2 \mathrm{~kg} / \mathrm{m} 2$ $(\mathrm{SD}=4.7$, range $17.6-51.2)$. Nine participants $(1.8 \%)$ had completed lower school education [German: Hauptschule], 37 (7.2\%) had completed middle school education [German: Realschule], 67 (13.1\%) had completed higher school education [German: Gymnasium], 134 (26.2\%) had completed vocational training, and $262(51.3 \%)$ had a university degree (data missing for 2 participants, .4\%). All participants gave written informed consent. The study was approved by the institutional review boards of the University of Munich (\#17544) and the Technical University of Munich (\#492/17S).

\section{Measures}

The set of questionnaires included items on demographic data, current (at the time of questionnaire completion) and highest adult weight, current height, eating preferences (e.g., vegetarianism, veganism), current and past psychotherapeutic treatment, as well as current use of psychotropic medication. Further, the questionnaires included several validated scales.

Symptoms of ON were measured with the DOS [5]. Its 10 items inquire orthorexic eating behaviors (e.g., "I have certain nutrition rules that I adhere to") and associated emotions (e.g., "If I eat something I consider unhealthy, I feel really bad") and are rated on a four-point scale ranging from "this does not apply to me" (1) to "this applies to me (4). Total scores range from 0 to 40 and values between 25 and 29 represent risk of ON, while values $\geq 30$ are considered to represent $\mathrm{ON}$.

The German version of the Patient Health Questionnaire (PHQ [22]) assesses symptoms related to somatic symptom disorders, depressive disorders, anxiety disorders, eating disorders, alcohol misuse, and psychosocial functioning. The items allow for calculating sum scores (depression, somatic symptoms, and general stress) and categorical variables representing syndromes (depression, somatic symptoms, panic, bulimia nervosa, anorexia nervosa, alcohol misuse).

The Short Evaluation of Eating Disorders (SEED; [23]) is a German screening for eating disorder symptoms, which allows for the calculation of total severity indices for anorexia nervosa and bulimia nervosa, respectively. Its items ask 
Table 1 Overview of studies employing the Düsseldorf Orthorexia Scale (DOS) in the general population

\begin{tabular}{|c|c|c|c|c|c|c|c|}
\hline \multirow[t]{2}{*}{ Study } & \multirow[t]{2}{*}{ Country } & \multicolumn{3}{|l|}{ Sample } & \multicolumn{2}{|l|}{ DOS total score } & \multirow{2}{*}{$\begin{array}{l}\text { Correlates of higher } \\
\text { DOS scores/ON }\end{array}$} \\
\hline & & Source & $\mathrm{N}(\%$ female $)$ & Age $M \pm S D$ & $\begin{array}{l}\% \text { ON (above } \\
\text { cutoff of } \geq 30 \text { ) }\end{array}$ & $M \pm S D$ & \\
\hline $\begin{array}{c}\text { Hennecke [17] in } \\
\text { Barthels [18] }\end{array}$ & Germany & General population & 2185 (n.a.) & n.a & 1.7 & n.a. & Female gender \\
\hline Barthels [5] & Germany & General population & $1340(70)$ & $29.3 \pm 11.0$ & 3 & $17.8 \pm 5.4$ & $\begin{array}{l}\text { Stronger drive for thin- } \\
\text { ness, stronger bulimic } \\
\text { symptoms, stronger } \\
\text { body dissatisfaction, } \\
\text { female gender }\end{array}$ \\
\hline Depa [6] & Germany & Students & $446(70)$ & $21.7 \pm 2.6$ & 3.3 & $18.4 \pm 5.3$ & Lower semester \\
\hline \multirow[t]{2}{*}{ Barthels [13] } & Germany & $\begin{array}{l}\text { Control sample for } \\
\text { patients with EDs } \\
\text { from general popula- } \\
\text { tion }\end{array}$ & $33(100)$ & $23.2 \pm 4.3$ & 3.2 & $17.4 \pm 4.6$ & n.a. \\
\hline & & $\begin{array}{l}\text { Control sample for } \\
\text { patients with OCD } \\
\text { from general popula- } \\
\text { tion }\end{array}$ & $30(40)$ & $41.4 \pm 13.3$ & & $15.9 \pm 5.7$ & \\
\hline Barthels [14] & Germany & $\begin{array}{l}\text { Control sample for } \\
\text { patients with EDs } \\
\text { from general popula- } \\
\text { tion }\end{array}$ & $30(100)$ & $22.10 \pm 7.43$ & n.a. & $19.0 \pm 4.5$ & n.a. \\
\hline Barthels [10] & Germany & $\begin{array}{l}\text { Control sample for } \\
\text { dieters, vegans, and } \\
\text { vegetarian }\end{array}$ & $258(77)$ & $29.8 \pm 11.0$ & 1.5 & $16.6 \pm 5.0$ & n.a. \\
\hline Chard [7] & USA & Students & $384(70)$ & $19.6 \pm 2.6$ & 8.0 & $20.0 \pm 6.0$ & $\begin{array}{l}\text { Vegetarianism, higher } \\
\text { satisfaction with cur- } \\
\text { rent diet }\end{array}$ \\
\hline Strahler [15] & Germany & General population & $713(80)$ & $29.4 \pm 11.2$ & 3.8 & $17.9 \pm 5.5$ & $\begin{array}{l}\text { Lower subjective } \\
\text { social status, lower } \\
\text { well-being, lower life } \\
\text { satisfaction, more } \\
\text { perceived stress, } \\
\text { stronger restraint eat- } \\
\text { ing, stronger eating } \\
\text { concern, stronger } \\
\text { weight concern, } \\
\text { stronger shape con- } \\
\text { cern, stronger general } \\
\text { eating pathology, } \\
\text { stronger depressive } \\
\text { symptoms, stronger } \\
\text { anxiety symptoms, } \\
\text { stronger obsessive } \\
\text { symptoms, stronger } \\
\text { compulsive symp- } \\
\text { toms, current psy- } \\
\text { chotherapy, current } \\
\text { psychotropic use }\end{array}$ \\
\hline Luck-Sikorski [12] & Germany & $\begin{array}{l}\text { Representative of } \\
\text { general population }\end{array}$ & 1007 (49) & $50.6 \pm .8$ & 6.9 & $19.25 \pm 6.11$ & $\begin{array}{l}\text { Univariate: higher } \\
\text { weight, lower educa- } \\
\text { tion, vegetarianism, } \\
\text { stronger depressive } \\
\text { symptoms } \\
\text { Multivariate: lower } \\
\text { education, veg- } \\
\text { etarianism, stronger } \\
\text { depressive symptoms }\end{array}$ \\
\hline
\end{tabular}


Table 1 (continued)

\begin{tabular}{|c|c|c|c|c|c|c|c|}
\hline \multirow[t]{2}{*}{ Study } & \multirow[t]{2}{*}{ Country } & \multicolumn{3}{|l|}{ Sample } & \multicolumn{2}{|l|}{ DOS total score } & \multirow{2}{*}{$\begin{array}{l}\text { Correlates of higher } \\
\text { DOS scores/ON }\end{array}$} \\
\hline & & Source & $\mathrm{N}(\%$ female $)$ & Age $M \pm S D$ & $\begin{array}{l}\% \text { ON (above } \\
\text { cutoff of } \geq 30 \text { ) }\end{array}$ & $M \pm S D$ & \\
\hline $\mathrm{He}[9]$ & China & Students & $1075(53)$ & $20.1 \pm 1.0$ & 7.8 & $21.5 \pm 5.4$ & $\begin{array}{l}\text { Male gender, stronger } \\
\text { eating inflexibility }\end{array}$ \\
\hline Parra-Fernández [8] & Spain & Students & $492(57)$ & $20.0 \pm 3.0$ & 10.5 & $17.52 \pm 5.2$ & $\begin{array}{l}\text { Stronger drive for } \\
\text { thinness, stronger } \\
\text { body dissatisfaction, } \\
\text { stronger, perfection- } \\
\text { ism, lower intero- } \\
\text { ceptive awareness, } \\
\text { stronger asceticism }\end{array}$ \\
\hline
\end{tabular}

$M$ mean, $S D$ standard deviation, $n . a$. not available, $E D$ s eating disorders, $O N$ orthorexia nervosa as defined by a DOS score $\geq 30$

for current height and weight, fear of gaining weight, body perception, and inappropriate compensatory behaviors. The latter three items are scored on five-point scales.

BMI and weight suppression (highest adult weight in $\mathrm{kg}$-current weight in $\mathrm{kg}$ ) were calculated as indices for current and past weight.

\section{Statistical analyses}

The prevalence of $\mathrm{ON}$ is reported as the percentage of persons scoring 30 or above on the DOS. As a very small number of persons scored above the cut-off, further analyses used the DOS total score as continuous measure of orthorexic tendencies. Subsequent statistical associations are, hence, not to be understood as phenomena related to a categorical representation of a clinical syndrome of $\mathrm{ON}$, but rather to higher or lower scores on the DOS.

Independent samples $t$-tests and univariate analyses of variance (ANOVAs) were conducted to compare mean DOS scores between levels of categorical variables. Statistically significant effects in the ANOVAs were followed-up with post hoc independent samples $t$-tests with Bonferroni-correction of the level of significance. Cohen's $d$ and partial $\eta^{2}$ were calculated as measures of effect size for the $t$ tests and the ANOVAs, respectively.

Associations of the DOS scores with continuous variables were examined with Pearson's $r$ correlation coefficients.

The adjusted association of DOS scores with the utilization of mental health care services was examined by three separate binary logistic regression analyses, with the use of the respective service (current psychotherapy, past psychotherapy, current use of psychotropic medication) as dichotomous (yes vs. no) dependent variable and the DOS score, the PHQ-D sum scores for depression, somatic symptoms, and stress, as well as the SEED anorexia and bulimia nervosa severity scales as continuous regressors.
Statistical analyses were performed with SPSS 25 for Macintosh. The two-tailed level of significance was set at .05 . The interpretation of results was based on effect sizes following conventional recommendations [24, 25].

\section{Results}

The mean DOS total score of the 511 participants was 16.47 $(S D=4.86$, range 10-34). According to classifications recommended for the DOS, $474(92.8 \%)$ had no ON, $25(4.9 \%)$ were at risk, and $12(2.3 \%)$ were supposed to have ON. The number of participants' included in the following analyses may vary due to missing data.

Table 2 displays the frequency of the categorical variables, the corresponding mean DOS scores and the tests statistics for the mean comparisons. Independent $t$ tests revealed statistically significantly higher mean DOS scores for women compared to men, persons with past psychiatric or psychotherapeutic treatment, current psychotherapeutic treatment, and psychotropic medication during the last year, as well as bulimia nervosa, somatoform syndrome, and alcohol syndrome according to the PHQ. Most effects, however, were of small to intermediate size. Large effect sizes were found for differences in DOS scores between persons with and without bulimia nervosa according to PHQ.

Univariate ANOVAs revealed differences in mean DOS scores for different levels of fear of weight gain according to the SEED and depressive syndrome according to PHQ. Table 3 displays the results of the respective post hoc independent $t$ tests. With regard to fear of weight, large effect sizes were found for the comparisons with the group of persons who reported to always experience this fear with them scoring higher on the DOS. Higher DOS sores with large effect sizes for the difference were found when comparing persons with major depressive syndrome with those with no or other depressive syndrome. 
Table 2 Association of orthorexia nervosa symptom total score as measured with the Düsseldorf Orthorexia Scale (DOS) with categorical variables. Results of the univariate analyses of variance

\begin{tabular}{|c|c|c|c|c|}
\hline Predictor & $N$ & $M(S D)$ DOS & Test statistics & Effect size \\
\hline $\operatorname{Sex}^{\mathrm{a}}$ & & & $t=2.38\left(467^{\mathrm{c}}\right), p=.018$ & $d=.20($ small $)$ \\
\hline Female & 324 & $16.83(5.24)$ & & \\
\hline Male & 187 & $15.84(4.06)$ & & \\
\hline Highest education $^{\mathrm{b}}$ & & & $F=.15(3,505), p=.932$ & partial $\eta^{2}=.001$ (none) \\
\hline Secondary school & 46 & $16.30(4.97)$ & & \\
\hline High school & 67 & $16.57(5.18)$ & & \\
\hline Occupational training & 134 & $16.69(4.96)$ & & \\
\hline University & 262 & $16.39(4.74)$ & & \\
\hline Past psychiatric or psychotherapeutic treatment $\mathrm{a}^{\mathrm{a}}$ & & & $t=4.88(508), p<.001$ & $d=.49($ small $)$ \\
\hline Yes & 135 & $18.19(4.87)$ & & \\
\hline No & 375 & $15.86(4.61)$ & & \\
\hline Current psychiatric or psychotherapeutic treatment ${ }^{\mathrm{a}}$ & & & $t=3.52(509), p<.001$ & $d=.59$ (intermediate) \\
\hline Yes & 39 & $19.08(5.32)$ & & \\
\hline No & 472 & $16.26(4.76)$ & & \\
\hline Psychotropic medication during last year ${ }^{\mathrm{a}}$ & & & $t=4.09(509), p<.001$ & $d=.65$ (intermediate) \\
\hline Yes & 44 & $19.30(5.74)$ & & \\
\hline No & 467 & $16.21(4.69)$ & & \\
\hline Fear of gaining weight $(\text { SEED item } 3)^{\mathrm{b}}$ & & & $F=26.71(4,505), p<.001$ & partial $\eta^{2}=.174$ (large) \\
\hline Never & 62 & $15.06(3.96)$ & & \\
\hline Seldom & 93 & $14.67(3.55)$ & & \\
\hline Sometimes & 161 & $15.54(4.26)$ & & \\
\hline Often & 122 & $17.11(4.60)$ & & \\
\hline Always & 72 & $21.02(4.87)$ & & \\
\hline PHQ bulimia nervosa ${ }^{a}$ & & & $t=5.01\left(39.99^{\mathrm{c}}\right), p<.001$ & $d=1.14$ (large) \\
\hline Yes & 38 & $21.38(6.40)$ & & \\
\hline No & 473 & $16.08(4.50)$ & & \\
\hline PHQ somatoform syndrome ${ }^{a}$ & & & $t=2.64\left(41.09^{c}\right), p=.012$ & $d=.60$ (intermediate) \\
\hline Yes & 39 & $19.12(6.65)$ & & \\
\hline No & 472 & $16.25(4.63)$ & & \\
\hline PHQ depressive syndromes ${ }^{\mathrm{b}}$ & & & $F=27.52(2,509), p<.001$ & partial $\eta^{2}=.098$ (intermediate) \\
\hline Major depressive syndrome & 16 & $24.09(6.27)$ & & \\
\hline Other depressive syndrome & 62 & $17.98(5.09)$ & & \\
\hline None & 433 & $15.97(4.49)$ & & \\
\hline PHQ alcohol syndrome ${ }^{a}$ & & & $t=.82(509), p=.415$ & $d=.14$ (none) \\
\hline Yes & 40 & $17.08(5.44)$ & & \\
\hline No & 471 & $16.42(4.81)$ & & \\
\hline
\end{tabular}

$M$ mean, $S D$ standard deviation, SEED short evaluation of eating disorders, PHQ Patient Health Questionnaire

${ }^{\mathrm{a}}$ Comparison of means with independent $t$ test

${ }^{\mathrm{b}}$ Comparison of means with univariate analysis of variance

${ }^{\mathrm{c}}$ Degrees of freedom corrected due to unequal variances

Table 4 displays the results for the associations of the DOS total score with continuous variables. Higher DOS total scores were statistically significantly associated with lower age, higher adult lifetime BMI, higher weight suppression, higher PHQ scores for depression, somatoform symptoms, and stress, as well as higher SEED scores for anorexia nervosa and bulimia nervosa. Yet, effect sizes were small or intermediately large.

Table 5 displays the results of the multiple binary logistic regression analyses for mapping the independent association of DOS scores with use of the mental health care system. Adjusted for depressive symptoms, stress, anorexia 
Table 3 Results of the post hoc independent $t$-tests for the univariate analyses of variance

\begin{tabular}{llll}
\hline Variable & $t(d f)$ & $p$ & Cohen's $d$ effect size \\
\hline Fear of gaining weight (SEED item 3) ${ }^{\mathrm{a}}$ & & .515 & .11 (none) \\
Never vs. seldom & $.65(153)$ & .447 & .12 (none) \\
Never vs. sometimes & $.76(221)$ & .003 & .47 (small) \\
Never vs. often & $2.98(182)$ & $<.001$ & 1.19 (large) \\
Never vs. always & $7.03(125.97)$ & .096 & .22 (small) \\
Seldom vs. sometimes & $1.67(252)$ & $<.001$ & .58 (intermediate) \\
Seldom vs. often & $4.39(212.96)$ & $<.001$ & 1.36 (very large) \\
Seldom vs. always & $8.21(111.18)$ & .003 & .36 (small) \\
Sometimes vs. often & $2.96(281)$ & $<.001$ & 1.15 (large) \\
Sometimes vs. always & $7.22(106.89)$ & $<.001$ & .77 (intermediate) \\
Often vs. always & $4.90(123.75)$ & & .44 (small) \\
PHQ depressive syndromes ${ }^{\mathrm{b}}$ & & .001 & 1.78 (large) \\
None vs. other depressive syndrome & $3.24(493)$ & $<.001$ & 1.14 (large) \\
None vs. major depressive syndrome & $5.13(15.57)$ & $<.001$ & \\
Other depressive syndrome vs. major & $4.08(76)$ & & \\
$\quad$ depressive syndrome & & & \\
\hline a Bonferroni-corrected level of significance $.05 / 10=.005$ & & \\
${ }^{b}$ Bonferroni-corrected level of significance $.05 / 3=.017$ & & \\
${ }^{\mathrm{c}}$ Degrees of freedom corrected due to unequal variances & &
\end{tabular}

Table 4 Association of Düsseldorf Orthorexia Scale (DOS) scores $>$ with continuous variables. Results of the bivariate correlation analyses

\begin{tabular}{llll}
\hline Predictor & $N$ & Pearson $r$ (effect size) & $p$ \\
\hline Age & 503 & -.15 (small) & .001 \\
Current BMI & 507 & .06 (none) & .158 \\
Highest adult lifetime BMI & 508 & .17 (small) & $<.001$ \\
Weight suppression & 505 & .23 (small) & $<.001$ \\
PHQ depression score & 501 & .37 (intermediate) & $<.001$ \\
PHQ somatoform score & 414 & .29 (small) & $<.001$ \\
PHQ stress score & 504 & .32 (intermediate) & $<.001$ \\
SEED anorexia nervosa score & 473 & .29 (small) & .004 \\
SEED bulimia nervosa score & 505 & .32 (intermediate) & $<.001$ \\
\hline
\end{tabular}

$B M I$ body mass index, SEED Short Evaluation of Eating Disorders, $P H Q$ Patient Health Questionnaire

nervosa symptoms, bulimia nervosa symptoms, age, and sex, the DOS score was not associated with past psychiatric or psychotherapeutic treatment, nor current psychiatric or psychotherapeutic treatment, nor use of psychotropic medication within the last year. Only depressive symptoms and age showed statistically significant associations.

\section{Discussion}

With regard to our study aims we found: (1) The prevalence of ON according to the DOS was $2.3 \%$, with another $4.9 \%$ being at risk of developing ON. Hence, the overall load of orthorexic tendencies in the sample was low and "higher DOS scores" are to be understood as relatively higher but not near or above a cut-off. (2) Only considering effects with at least intermediate size, higher mean DOS score were found for persons, who reported to always experience a fear of gaining weight and who met the classifications of bulimia nervosa, somatoform syndrome, or major depressive syndrome according to the PHQ. Correlational analyses suggested higher DOS scores relating to higher PHQ depression and stress scores, as well as higher SEED bulimia nervosa scores. (3) While persons with past or current psychiatric treatment also showed higher DOS scores in univariate analyses, these effects vanished in multivariate logistic regression analyses. The probability of using or having used mental health services only increased with higher depressive symptoms according to PHQ and higher age.

With values around $1.5 \%$, only two studies [10, 17] reported lower prevalence estimates for $\mathrm{ON}$ based on the DOS than we found, with the study by Hennecke being more than 10 years old and employing a preliminary version of the DOS. Among the studies with the DOS, there seems to be no clear pattern connecting sample characteristics, such as sample size, age, or percentage of female participants with the prevalence of ON. It is striking, however, that in nonrepresentative samples from the German general population, estimates lie around $3 \%$ [5, 6, 10, 13, 15, 17], while the only representative German study [12] and all non-German studies yield values ranging from 7 to $10 \%[7,9,16]$. While differences might be attributable to the younger mean age of the student samples used for validating the Chinese, Spanish, 
Table 5 Adjusted association of DOS total scores with utilization of mental health care services. Results of the binary logistic regression analyses

\begin{tabular}{llll}
\hline Model & Odds ratio & $95 \%$ CI & $p$ \\
\hline 1: Past psychiatric/psychotherapeutic treatment: Nagelkerke's & \\
$\mathrm{R}^{2}=.22$ & & & \\
PHQ depression score & 1.21 & $1.08-1.36$ & .002 \\
PHQ stress score & .95 & $.86-1.15$ & .945 \\
SEED anorexia nervosa score & 1.08 & $.36-3.27$ & .894 \\
SEED bulimia nervosa score & 1.60 & $.84-3.03$ & .152 \\
Age in years & 1.02 & $1.00-1.03$ & .039 \\
Male gender & .62 & $.36-1.06$ & .079 \\
DOS total score & 1.04 & $.99-1.10$ & .103 \\
2: Current psychiatric/psychotherapeutic treatment: Nagelkerke's \\
R ${ }^{2}=.23$ & & & \\
PHQ depression score & 1.11 & $.95-1.30$ & .190 \\
PHQ stress score & 1.16 & $.95-1.43$ & .149 \\
SEED anorexia nervosa score & .82 & $.11-6.35$ & .849 \\
SEED bulimia nervosa score & 2.04 & $.80-5.17$ & .135 \\
Age in years & 1.00 & $.98-1.03$ & .772 \\
Male gender & .41 & $.14-1.19$ & .101 \\
DOS total score & 1.00 & $.92-1.08$ & .983 \\
3: psychotropic medication during last year: Nagelkerke's R & $=.20$ \\
PHQ depression score & 1.22 & $1.04-1.43$ & .013 \\
PHQ stress score & 1.00 & $.82-1.22$ & .996 \\
SEED anorexia nervosa score & 1.76 & $.26-12.16$ & .564 \\
SEED bulimia nervosa score & .93 & $.37-2.35$ & .885 \\
Age in years & 1.02 & $1.00-1.04$ & .106 \\
Male gender & .58 & $.23-1.45$ & .244 \\
DOS total score & 1.05 & $.98-1.13$ & .198 \\
\hline
\end{tabular}

95\% CI 95\% confidence interval of the odds ratio, SEED short evaluation of eating disorders, $P H Q$ patient health questionnaire, DOS Düsseldorf Orthorexia Scale

and English versions of the DOS, the high estimate of the representative German sample comes as a surprise. LuckSikorski et al. [12] argue that the high prevalence in their sample might result from an increased incidence of ON over the years. The more recent and lower prevalence estimates in our and another German study [15] contradict this explanation and suggest that variables inherent to the samples or study designs explain the discrepancies.

It is still debated whether ON represents a circumscribed clinical entity and whether this entity should be allocated to the eating disorders $[1,26]$. Orthorexic tendencies are strongly associated with core eating disorder symptoms like body dissatisfaction and drive for thinness $[5,15,16,27]$, which was further confirmed by our data. Together with a high prevalence of ON in anorexia nervosa [14], this finding cannot easily be reconciled with the proposition that restrictive eating in $\mathrm{ON}$ is not aimed at weight loss but at healthy eating [1]. However, there was no association between orthorexic tendencies and measures of past and present weight in our sample, unlike to what is known from eating disorders [28, 29]. Also, the lack of an association between orthorexic tendencies and symptoms of anorexia nervosa in our sample does not concur with what is reported for clinical and non-clinical samples (see Table 1; [13, 14]). There was, however, tentative evidence in our sample for an association between orthorexic tendencies and symptoms of bulimia nervosa, which corresponds with previous studies (see Table 1, e.g., [5]) and suggests a relationship between orthorexic tendencies and impulsive rather than restrictive eating. The counterintuitive nature of this association warrants further examination.

The association with other psychiatric symptoms, especially those of depression, concur with preliminary results [12]. Even though two studies using the DOS reported conflicting results with regard to sex differences [9, 17], the small effect size for differences in DOS scores between men and women in our study confirms the general literature, which suggests no association of measures of $\mathrm{ON}$ with sex [19]. The notion that ON is more prevalent in lower educational levels [12] was not supported by our data.

The only study examining the use of mental health care in relationship to $\mathrm{ON}$ found higher rates of current psychotherapy and use of psychotropic medication to be associated with higher ON scores [15]. Our univariate analyses replicated these relationships and extended them by indicating that persons with higher DOS scores were more likely to having received psychotherapy or psychiatric treatment in the past. When adjusting for other psychiatric symptoms, however, these associations vanished and depressive symptoms emerged as independent predictor together with higher age. These results suggest that orthorexic tendencies alone might not be a primary reason for seeking treatment.

Overall, it seems as orthorexic tendencies are related to general mental distress and some symptoms that are typical for eating disorders. Given the high comorbidity between eating disorders and depressive and other mental disorders $[30,31]$, this finding is compatible with the notion that $\mathrm{ON}$ in its clinical form may rather be some form of eating disorder. This, however, does not contradict the conceptualization of $\mathrm{ON}$ being exclusively aimed at healthy eating.

Our study is limited by the fact that the sample was derived from the general population, yet, drawn from studies on health and nutrition, which may have introduced bias into the sample through including a substantial proportion of persons with either specific interests in nutrition or related health problems. The low prevalence of ON that is in line with several other studies from the general population, however, contradicts this notion. Further, we had no means to assess any difference between those who returned the questionnaire and those who did not. 


\section{Conclusions}

Given the relatively low prevalence of $\mathrm{ON}$ in our study and other samples, the symptomatic overlap with established eating disorders, and the fact that stronger ON symptoms alone do not seem to be a reason for consulting mental health care professionals, there is little indication to view $\mathrm{ON}$ as an independent public health issue. Rather, ON may be an eating style overlapping with eating disorders and a maladaptive coping mechanism [14] in the face of general stress, including growing public pressure to eat healthy, and depression.

\section{What is already known on this subject?}

Orthorexic symptoms show varying prevalence rates in the general population depending on instrument and sample characteristics, as well as unspecific associations with measures of psychiatric symptoms.

\section{What this study adds?}

The study substantiates previous prevalence estimates and emphasizes that orthorexic tendencies relate to general mental distress, but are no independent reason for utilizing health care services.

Acknowledgements Open Access funding provided by Projekt DEAL. Data related to this paper was in part gathered in the framework of the enable cluster (https://enable-cluster.de) BMBF. The authors thank Margot Maier and Theresa Drabsch for supporting data collection.

Funding The studies were funded in part by a grant of the German Ministry for Education and Research (BMBF, 01EA1409A), by the Else Kroener-Fresenius-Foundation (Bad Homburg, Germany) and by the Helmholtz cross-program topic Metabolic Dysfunction.

\section{Compliance with ethical standards}

Conflict of interest The authors declare that they have no conflict of interest.

Ethical approval All procedures performed in studies involving human participants were in accordance with the ethical standards of the institutional and/or national research committee and with the 1964 Helsinki declaration and its later amendments or comparable ethical standards.

Informed consent All individual participants included in the study were informed about protection of their data and voluntariness of the participation and gave their consent.

Open Access This article is licensed under a Creative Commons Attribution 4.0 International License, which permits use, sharing, adaptation, distribution and reproduction in any medium or format, as long as you give appropriate credit to the original author(s) and the source, provide a link to the Creative Commons licence, and indicate if changes were made. The images or other third party material in this article are included in the article's Creative Commons licence, unless indicated otherwise in a credit line to the material. If material is not included in the article's Creative Commons licence and your intended use is not permitted by statutory regulation or exceeds the permitted use, you will need to obtain permission directly from the copyright holder. To view a copy of this licence, visit http://creativecommons.org/licenses/by/4.0/.

\section{References}

1. Cena H, Barthels F, Cuzzolaro M et al (2019) Definition and diagnostic criteria for orthorexia nervosa: a narrative review of the literature. Eat Weight Disord 24:209-246. https://doi.org/10.1007/ s40519-018-0606-y

2. Missbach B, Hinterbuchinger B, Dreiseitl V et al (2015) When eating right, is measured wrong! A validation and critical examination of the ORTO-15 questionnaire in German. PLoS ONE 10:1-15. https://doi.org/10.1371/journal.pone.0135772

3. Valente M, Syurina EV, Donini LM (2019) Shedding light upon various tools to assess orthorexia nervosa: a critical literature review with a systematic search. Eat Weight Disord Stud Anorexia Bulim Obes. https://doi.org/10.1007/s40519-019-00735-3

4. Meule A, Holzapfel C, Brandl B et al (2020) Measuring orthorexia nervosa: a comparison of four self-report questionnaires. Appetite 146:1-6. https://doi.org/10.1016/j.appet.2019.104512

5. Barthels F, Meyer F, Pietrowsky R (2015) Die düsseldorfer orthorexie skala - konstruktion und evaluation eines fragebogens zur erfassung orthorektischen ernährungsverhaltens. Z Klin Psychol Psychother 44:97-105. https://doi.org/10.1026/1616-3443/a0003 10

6. Depa J, Schweizer J, Bekers SK et al (2017) Prevalence and predictors of orthorexia nervosa among German students using the 21-item-DOS. Eat Weight Disord 22:193-199. https://doi. org/10.1007/s40519-016-0334-0

7. Chard CA, Hilzendegen C, Barthels F, Stroebele-Benschop N (2019) Psychometric evaluation of the English version of the düsseldorf orthorexie scale (DOS) and the prevalence of orthorexia nervosa among a U.S. student sample. Eat Weight Disord 24:275-281. https://doi.org/10.1007/s40519-018-0570-6

8. Parra-Fernández ML, Onieva-Zafra MD, Fernández-Muñoz JJ, Fernández-Martínez E (2019) Adaptation and validation of the Spanish version of the DOS questionnaire for the detection of orthorexic nervosa behavior. PLoS ONE 14:e0216583. https:// doi.org/10.1371/journal.pone.0216583

9. He J, Ma H, Barthels F, Fan X (2019) Psychometric properties of the Chinese version of the Düsseldorf Orthorexia Scale: prevalence and demographic correlates of orthorexia nervosa among Chinese university students. Eat Weight Disord 24:453-463. https ://doi.org/10.1007/s40519-019-00656-1

10. Barthels F, Meyer F, Pietrowsky R (2018) Orthorexic and restrained eating behaviour in vegans, vegetarians, and individuals on a diet. Eat Weight Disord 23:159-166. https://doi.org/10.1007/ s40519-018-0479-0

11. Rudolph S, Göring A, Jetzke M et al (2016) Zur Prävalenz von orthorektischem Ernährungsverhalten bei sportlich aktiven Studierenden. Dtsch Z Sportmed 2017:10-13. https://doi.org/10.5960/ dzsm.2016.262

12. Luck-Sikorski C, Jung F, Schlosser K, Riedel-Heller SG (2019) Is orthorexic behavior common in the general public? A large representative study in Germany. Eat Weight Disord 24:267-273. https://doi.org/10.1007/s40519-018-0502-5

13. Barthels F, Meyer F, Huber T, Pietrowsky R (2017) Analyse des orthorektischen Ernährungsverhaltens von Patienten mit Essstörungen und mit Zwangsstörungen. Z Klin Psychol Psychother 46:32-41. https://doi.org/10.1026/1616-3443/a000399

14. Barthels F, Meyer F, Huber T, Pietrowsky R (2017) Orthorexic eating behaviour as a coping strategy in patients with anorexia 
nervosa. Eat Weight Disord 22:269-276. https://doi.org/10.1007/ s40519-016-0329-x

15. Strahler J, Hermann A, Walter B, Stark R (2018) Orthorexia nervosa: a behavioral complex or a psychological condition? J Behav Addict 7:1143-1156. https://doi.org/10.1556/2006.7.2018.129

16. Parra-Fernández ML, Onieva-Zafra MD, Fernández-Martínez E et al (2019) Assessing the prevalence of orthorexia nervosa in a sample of university students using two different self-report measures. Int J Environ Res Public Health 16:2459. https://doi. org/10.3390/ijerph16142459

17. Hennecke A (2007) Untersuchungen zur Prävalenz der Orthorexia nervosa. Heinrich-Heine-Universität Düsseldorf, Unveröff entlichte Diplomarbeit

18. Barthels F, Pietrowsky R (2012) Orthorektisches Ernährungsverhalten - Nosologie und Prävalenz. PPmP Psychother Psychosom Medizinische Psychol 62:445-449. https://doi. org $/ 10.1055 / \mathrm{s}-0032-1312630$

19. Strahler J (2019) Gender differences in orthorexic eating behaviors: a systematic review and meta-analytic integration. Nutrition. https://doi.org/10.1016/j.nut.2019.06.015

20. Drabsch T, Holzapfel C, Stecher L et al (2018) Associations between C-reactive protein, insulin sensitivity, and resting metabolic rate in adults: a mediator analysis. Front Endocrinol (Lausanne) 9:1-9. https://doi.org/10.3389/fendo.2018.00556

21. Brandl B, Skurk T, Rennekamp R, et al (under review) A phenotyping platform to characterize healthy individuals across four stages of life—an enable study. https://doi.org/10.1007/s4051 9-020-00901-y

22. Gräfe K, Zipfel S, Herzog W, Löwe B (2004) Screening psychischer störungen mit dem "Gesundheitsfragebogen für Patienten (PHQ-D)". Ergebnisse der Deutschen validierungsstudie. Diagnostica 50:171-181. https://doi.org/10.1026/0012-1924.50.4.171

23. Bauer S, Winn S, Schmidt U, Kordy H (2005) Construction, scoring and validation of the Short Evaluation of Eating Disorders (SEED). Eur Eat Disord Rev 13:191-200. https://doi.org/10.1002/ erv.637
24. Sawilowsky SS (2009) New effect size rules of thumb. J Mod Appl Stat Methods 8:597-599. https://doi.org/10.22237/jmasm $/ 1257035100$

25. Cohen J (1988) Statistical power analysis for the behavioral sciences, 2. Lawrence Erlbaum Associates, Hillsdale, NJ

26. Strahler J, Stark R (2020) perspective: classifying orthorexia nervosa as a new mental illness-much discussion, little evidence. Adv Nutr 2019:1-6. https://doi.org/10.1093/advances/nmaa012

27. Brytek-Matera A, Gramaglia C, Gambaro E et al (2018) The psychopathology of body image in orthorexia nervosa. J Psychopathol 24:133-140

28. Lowe MR, Piers AD, Benson L (2018) Weight Suppression in eating disorders: a research and conceptual update. Curr Psychiatry Rep. https://doi.org/10.1007/s11920-018-0955-2

29. Hessler JB, Schlegl S, Greetfeld M, Voderholzer U (2019) Dimensions within 24 weight history indices and their association with inpatient treatment outcome in adults with anorexia nervosa: analysis of routine data. J Eat Disord 7:1-16. https://doi.org/10.1186/ s40337-019-0249-z

30. Voderholzer U, Hessler-Kaufmann JB, Lustig L, Läge D (2019) Comparing severity and qualitative facets of depression between eating disorders and depressive disorders: analysis of routine data. J Affect Disord 257:758-764. https://doi.org/10.1016/j. jad.2019.06.029

31. Keski-Rahkonen A, Mustelin L (2016) Epidemiology of eating disorders in Europe: prevalence, incidence, comorbidity, course, consequences, and risk factors. Curr Opin Psychiatry 29:340-345. https://doi.org/10.1097/YCO.0000000000000278

Publisher's Note Springer Nature remains neutral with regard to jurisdictional claims in published maps and institutional affiliations. 